\title{
Preliminary Study of Chitosan Coating Silica Derived from Geotermal Solid Waste
}

\author{
S. Silviana ${ }^{*}$, Annisya Noorpasha, Muhammad Miftahur Rahman \\ Department of Chemical Engineering, Faculty of Engineering, Diponegoro University, Jl. Prof. Sudarto SH Kampus Tembalang, 50275 \\ Semarang, Indonesia
}

Received February 25, 2020; Revised May 20, 2020; Accepted May 29, 2020

Copyright $(2020$ by authors, all rights reserved. Authors agree that this article remains permanently open access under the terms of the Creative Commons Attribution License 4.0 International License

\begin{abstract}
Purpose: The purposes of this research are to study preparation of chitosan coating silica aerogel derived from solid geothermal waste as adsorbent of $\mathrm{CO}_{2}$ and $\mathrm{CH}_{4}$ separation and to study $\mathrm{CO}_{2}$ adsorption kinetics on chitosan coating silica aerogel by Pseudo First Order and Second Order methods. Methodology was conducted consisting of several steps. First, geothermal silica was leached with $\mathrm{H}_{2} \mathrm{SO}_{4} 20 \%$ 1: $5 \mathrm{w} / \mathrm{v}$. Then, chitosan was added into silica with ratio of 1.3: 10, 1.5: 10, 1.9: 10, 2.2: 10, and 2.4: 10 $\mathrm{w} / \mathrm{v}$. Isopropyl alcohol was added to silica sol to form hydrogel and remained in gelation. The addition of n-hexane was carried out to occur the solvent exchange process. The gel was dried by ambient pressure drying method. $\mathrm{CO}_{2}$ in biogas was removed of using $20 \mathrm{~g}$ of adsorbent chitosan coating silica aerogel. The experimental adsorption kinetics analyzed by both pseudo first and second order kinetics model. Results showed that impurities in geothermal silica required to be purified and it can be synthesized into silica aerogel. The remaining geothermal can act as adsorbents to silica aerogel coated with chitosan by using packed column. The data obtained was kinetics data from the pseudo first and second order method. The silica from solid geothermal waste has the potential as $\mathrm{CO}_{2}$ adsorbent. Applications/ Originality/ Value: It was confirmed that silica from solid geothermal waste can be used as $\mathrm{CO}_{2}$ adsorbent. Therefore, the improvement of innovation in the future of this research is to prepare chitosan coating silica aerogel as $\mathrm{CO}_{2}$ adsorbent.
\end{abstract}

Keywords Chitosan, $\mathrm{CH}_{4}, \mathrm{CO}_{2}$, Geothermal Silica, Kinetics, Pseudo First Order, Pseudo Second Order

\section{Introduction}

The availability of oil and gas in Indonesia is getting lower (BPPT, 2017). It is predicted that in 2025 - 2050 Indonesia will become an importer of oil and natural gas (BPPT, 2017). Nowadays, diversification of renewable energy has been strived, such as bioethanol (Melikoglu \& Turkmen, 2019), biodiesel (Gozmen Şanli, Uludamar, \& Özcanli, 2019), and biogas (Khalil, Berawi, Heryanto, \& Rizalie, 2019). However, the process of utilizing these fuels still has limitations in the refining process, both in terms of separation efficiency and costs used, especially for the use of biogas.

Biogas produced from biomass fermentation has been widely used. However, the biogas calorific value is still below the standard (Al Mamun \& Torii, 2017) and the carbon dioxide $\left(\mathrm{CO}_{2}\right)$ gas content in biogas is still $25-45 \%$ so that it can cause corrosion (Kusrini et al., 2017). In addition to reducing the calorific value, the presence of $\mathrm{CO}_{2}$ gas also makes the biogas operation process uneconomical. Therefore the process of purifying biogas from $\mathrm{CO}_{2}$ must be carried out to increase and maximize the use of biogas.

Several processes have been developed for biogas purification to achieve high biogas calorific values, such as absorption process using amine solvent (Hairul, Shariff, \& Bustam, 2017), membranes (Kusworo, Qudratun, Utomo, Ramadhan, \& Indriyanti, 2018), and adsorption using zeolites (Chen et al., 2017). The weaknesses of these processes are that they require high energy, expensive costs for the regeneration process, low adsorption capacity, and are corrosive (Kong, Shen, Cui, \& Fan, 2015).

To cover up the existing process, research has been developed on polyethyleneimine (PEI) which has been synthesized and shows largest $\mathrm{CO}_{2}$ adsorption capacity of $93.4 \mathrm{mg} \mathrm{CO} / \mathrm{g}$ adsorbent at $1 \mathrm{~atm}$ pressure \& $25-100^{\circ} \mathrm{C}$ temperature. However, aminated silica synthesis implicates toxic 3-aminopropyltriethoxicylicate reagents that can damage human mucous membranes and respiratory tracts, and toluene usage as solvent in an amount 100 times the dissolved silica mass. Exaggerated uses of aromatic 
solvents and toxic reagents have to be evaded (Zhang et al., 2007). Several studies have covered this weakness by replacing amine compound with chitosan.

The use of chitosan as an adsorbent has been widely researched, one of which is Sneddon et al. (2015) which has coating chitosan into silica gel and has reached an adsorption capacity of $123 \mathrm{~m} \mathrm{~m}^{2} \mathrm{~g}^{-1}$ with chitosan composites of $19 \% \mathrm{w}$. Nevertheless, the low capacity is related to silica gel's surface area, which is only $186 \mathrm{~m}^{2} \mathrm{~g}^{-1}$, too low for notable adsorption. To maximize chitosan's potential as $\mathrm{CO}_{2}$ adsorbent, a much higher amount of supporting material is needed. Therefore, adsorbents such as silica aerogel can be used to overcome difficulties in terms of biogas purification, non-toxic, easily regenerated, and have higher porosity.

Silica aerogel is a material with a high specific surface area, high porosity, low density, and easily regenerated (de Fátima Júlio, Soares, Ilharco, Flores-Colen, \& de Brito, 2016). In the study of Feng et al. (2018), silica aerogel has a surface area of $945.8 \mathrm{~m}^{2} \mathrm{~g}^{-1}$ so it has potential to be an adsorbent for effective purification of $\mathrm{CO}_{2}$ in biogas. However, the application of silica aerogel as an adsorbent for biogas purification is limited due to the high cost of manufacture so it is necessary to modify the porosity to maximize the use of silica aerogel.

Porosity is an important property for adsorbent. Distribution of pore size, surface area and pore volume can involve the dimentions and interactions of surface and gas. Therefore, porosity can play an important role in gas mixture separation (Yi et al., 2015). Modification of silica aerogel porosity has been carried out using $1 \mathrm{~N} \mathrm{HCl}$ volume variation and Cetyl trimethylammonium bromide (CTAB) surfactant to produce mesoporous silica aerogel with porosity of $12 \mathrm{~nm}$ and $2.9 \mathrm{~nm}$ (Lee et al., 2017; Vazquez, Gonzalez, Ferrari, \& Castro, 2017). Silica aerogel's porosity can be engineered so silica aerogel can be more selective when it functions as adsorbent.

Thus, the innovation of this research is the development of chitosan coating silica aerogel adsorbent as a $\mathrm{CO}_{2}$ purification adsorbent in biogas. Different from previous studies, chitosan coating silica aerogel has high selectivity, good thermal stability, and is easily regenerated. This is expected to increase the kinetics of adsorption on $\mathrm{CO}_{2}$ so it can be used to reduce the level of $\mathrm{CO}_{2}$ gas in biogas. In addition, with the modification of porosity and high surface area in silica aerogel coated with chitosan, the capacity to capture $\mathrm{CO}_{2}$ will increase. This study also utilizes silica aerogel material made from silica from geothermal solid waste in Dieng. Geothermal silica as an effort to create products that have high economic value to waste utilization, it is expected that the coating of chitosan with silica aerogel and modified porosity with $\mathrm{HCl}$ can produce sustainable adsorbent for the purification of $\mathrm{CO}_{2}$ in biogas that is effective, energy efficient, easily regenerated, and preserves the environment.

The purposes of this research are to study the synthesis of chitosan coating silica aerogel made from solid geothermal waste in Dieng as adsorbent for separating $\mathrm{CO}_{2}$ and $\mathrm{CH}_{4}$, and to study $\mathrm{CO}_{2}$ adsorption kinetics on chitosan coating silica aerogel by Pseudo First Order and Pseudo Second Order methods.

\section{Material and Method}

\section{Material}

Geothermal solid waste from Dieng Indonesia, Sulfuric Acid $\left(\mathrm{H}_{2} \mathrm{SO}_{4}\right)$, Sodium Hydroxide $(\mathrm{NaOH})$ Hydrochloric Acid $(\mathrm{HCl}), n-H e x a n e$ and IPA were procured from p.a Merck, chitosan was delivered from CV Nura Jaya, Methane $\left(\mathrm{CH}_{4}\right)$ and Carbon Dioxide $\left(\mathrm{CO}_{2}\right)$ were supplied from PT Samator Surabaya (p.a Merck), and Aquadest.

\section{Method}

\section{Adsorbent preparation}

Dieng geothermal silica sample was dried at $110^{\circ} \mathrm{C}$ for 24 hours, followed by leaching process for 1 hour 45 minutes at $100^{\circ} \mathrm{C}$ with a ratio of silica and $\mathrm{H}_{2} \mathrm{SO}_{4} 20 \%$ 1: 5 $\mathrm{w} / \mathrm{v}$. This was done to remove organic impurities and metals in Dieng geothermal silica. Second, washing geothermal silica solution using aquadest to $\mathrm{pH}$ 7. Drying of sample is carried out at a temperature of $105^{\circ} \mathrm{C}$ to a constant weight using a vacuum oven to purify silica powder. To make soles, 10 grams of fine granules from geothermal silica were extracted in $100 \mathrm{ml}$ of $\mathrm{NaOH} 6 \mathrm{~N}$ for 1 hour under $98^{\circ} \mathrm{C}$ heating. Then the mixture was cooled down to $30^{\circ} \mathrm{C}$. Samples were filtered using filter paper (whatman 41), the results of this filter in the form of residues namely solid impurity and filtrate in the form of sodium silicate $\left(\mathrm{Na}_{2} \mathrm{O} \cdot \mathrm{SiO}_{2}\right)$. To form gelation, the filtrate that has been obtained is cooled to room temperature and stirred with magnetic stirrer for 30 minutes. The filtrate was titrated with $\mathrm{HCl} 1 \mathrm{~N}$ to $\mathrm{pH} 7$ to produce silica gel. The gel is aged for 18 hours at room temperature, then filtered. Then, chitosan was added with silica and chitosan ratio of 1.3: 10, 1.5: 10, 1.9: 10, 2.2: 10, and 2.4: $10 \mathrm{w} / \mathrm{v}$ (Sneddon, Ganin, \& Yiu, 2015). Samples were washed with distilled water for 5 times and IPA (60 $\mathrm{ml}$ ) was added to silica sol to form hydrogel and gelated for 10 seconds. After the formation of hydrogels, the addition of $n$-hexane is carried out to occur the solvent exchange process. This is done for surface modification of the hydrogel with the ratio of hydrogel and n-hexane 0.75 from a base of $60 \mathrm{ml}$ water glass. Then it continued with aging for 3-5 hours (Lee et al., 2017). A mixture of solutions containing silane and solvent agents. The gel is dried by Ambient Pressure Drying method to evaporate the liquid in a vacuum oven at a temperature of $70^{\circ} \mathrm{C}$ for 1 hour and $150^{\circ} \mathrm{C}$ for 1 hour until dry to evaporate the liquid to produce chitosan coating silica aerogel (Lee et al., 2017). 


\section{Adsorbent Test}

The chitosan coating silica aerogel was measured by weight before being put into the column. After that, put in 20 gram chitosan coating silica to packed column. Then, the flow of methane and carbon dioxide gas each flowed at a rate of $600 \mathrm{ml} / \mathrm{min}$. Then the gas that had been mixed was regulated its flow velocity with variations of 100 and 500 $\mathrm{ml} / \mathrm{min}$ seen through a flow meter. The gas mixture was flowed into the adsorption column containing chitosan coating silica aerogel as an absorbent of $\mathrm{CO}_{2}$. After the gas was flowed, the chitosan coating silica aerogel was measured by weight until there was no change in the weight of chitosan coating silica aerogel and the equilibrium time was obtained. This showed that the adsorption had reached saturation so that the adsorption equilibrium time was obtained (Kusrini et al., 2017).

\section{Analysis of $\mathrm{CO}_{2}$ Adsorption Kinetics}

Pseudo first and second order models can be utilized to evaluate the kinetics of gas adsorption on silica aerogel (Loganathan et al., 2014).

\section{A. Pseudo first order}

Based on equation $(1), \mathrm{q}_{\mathrm{t}}(\mathrm{mmol} / \mathrm{g})$ and $\mathrm{q}_{\mathrm{e}}(\mathrm{mmol} / \mathrm{g})$ indicate the amount of the adsorbed $\mathrm{CO}_{2} . \mathrm{q}_{\mathrm{e}}$ can be obtained when the equilibrium of the weight of silica aerogel after $\mathrm{CO}_{2}$ gas flowed under conditions of constant temperature and pressure. Whereas $\mathrm{q}_{\mathrm{t}}$ is obtained when silica aerogel absorbs $\mathrm{CO}_{2}$ gas at a certain time by measuring its weight. Weight difference $(\Delta \mathrm{W})$ will get the value of qe and $\mathrm{q}_{\mathrm{t}} \cdot \mathrm{k}_{\mathrm{f}}\left(\mathrm{s}^{-1}\right)$ indicates first order constants (Loganathan, et al., 2014)

$$
\frac{d q}{d t}=k_{f}\left(q_{e}-q_{t}\right)
$$

To get the $\mathrm{k}_{\mathrm{f}}$ value, boundary condition (namely $\mathrm{t}=0$, $\mathrm{q}_{\mathrm{t}}=0$, and $\mathrm{t}=\mathrm{t}_{\infty}, \mathrm{q}_{\mathrm{t}}=\mathrm{q}_{\mathrm{e}}$ ) is integrated to equation (1), so $\mathrm{k}_{\mathrm{f}}$ is obtained (Ghrab et al., 2017).

$$
\mathrm{q}_{\mathrm{t}}=\mathrm{q}_{\mathrm{e}}\left(1-\mathrm{e}^{-\mathrm{kft}}\right)
$$

\section{B. Pseudo second order}

The pseudo-second order model is based on the hypothesis that the rate of adsorption is related to the square of the number of vacant adsorption sites linearly (Kamal et al., 2017), therefore the rate of kinetic can be showed as:

$$
\frac{d q t}{d t}=k_{s}\left(q_{e}-q_{t}\right)^{2}
$$

$\mathrm{q}_{\mathrm{e}}$ can be obtained when the equilibrium of the weight of silica aerogel after $\mathrm{CO}_{2}$ gas flowed under conditions of constant temperature and pressure. Whereas $\mathrm{q}_{\mathrm{t}}$ is obtained when silica aerogel absorbs $\mathrm{CO}_{2}$ gas at a certain time by measuring its weight. Weight difference $(\Delta \mathrm{W})$ will get the value of $\mathrm{q}_{\mathrm{e}}$ and $\mathrm{q}_{\mathrm{t}}$. The value of $\mathrm{k}_{\mathrm{s}}\left(\mathrm{g} \mathrm{mmol}^{-1} \mathrm{~s}^{-1}\right)$ is the constant of second order rate. To get $\mathrm{k}_{\mathrm{s}}$ value by applying and integrating the boundary conditions $\mathrm{t}=0, \mathrm{q}_{\mathrm{t}}=0$, and $\mathrm{t}=\mathrm{t}_{\infty}$, $\mathrm{q}_{\mathrm{t}}=\mathrm{q}_{\mathrm{e}}$ in equation (3) turns into:

$$
q_{t}=\frac{q^{2} e^{k_{s} t}}{1+q_{e} k_{s} t}
$$

The values of $k_{s}$ for all analyzed temperature and pressure conditions are gained from equation (4).

An error function from the assigned standard deviation is determined by a method expressed in the literature to assume the exactness of the fit of the kinetic models (Loganathan et al., 2014),

$$
\Delta q(\%)=\sqrt{\frac{\sum\left[\left(q_{\text {exp }}-q_{\text {model }}\right) / q_{\text {model }}\right]^{2}}{N-1}} \times 100 \%
$$

$\Delta \mathrm{q}(\%)$ is the defined standard deviation, and $\mathrm{q}_{\mathrm{exp}}$ \& $\mathrm{q}_{\text {model }}$ are the calculated and experimental number of the adsorbed $\mathrm{CO}_{2}$, and number of available data points in each isotherm is described as N (Loganathan et al., 2014).

\section{Result and Discussion}

\subsection{Preparation of Silica Purification}

Silica waste geotermal has high metal oxide content as can be seen in Fig. 1. This must be removed because it will decrease the quality of pure silica and reduce the metal impurity content. One of the standard specifications required in $\mathrm{Na}_{2} \mathrm{SiO}_{4}$ is to contain silica of approximately 97\% (Ranawat, 2000). Purification of metal oxide particles contained in geothermal silica can be reduced using acid solution (Anas Boussaa, Kheloufi, Boutarek Zaourar, \& Bouachma, 2017; Purnomo, Dalanta, Oktaviani, \& Silviana, 2018). Research using silica purification with acid has been investigated (Boussaa et al., 2017). The purification of geothermal silica using $\mathrm{H}_{2} \mathrm{SO}_{4}$ solution can be seen in Fig. 1, and the results showed that the optimum silica product was produced from purification using $20 \%$ $\mathrm{v} / \mathrm{v} \mathrm{H}_{2} \mathrm{SO}_{4}$ with silica content of $98.2 \%$ in table 1 . The reaction between $\mathrm{H}_{2} \mathrm{SO}_{4}$ and metal oxide caused damage to ionic bonds in metal compounds with oxygen. $\mathrm{SiO}_{4}{ }^{2-}$ ions are highly reactive to metals, especially alkali metals and from transition groups such as $\mathrm{Fe}, \mathrm{Ni}, \mathrm{Cu}, \mathrm{Pb}$ and others. These ions will bind the impurities found in the sample to form sulfate salts from metals. $\mathrm{SO}_{4}{ }^{2-}$ ions bind to metal compounds to form sulfate metal compounds when the $\mathrm{H}^{+}$ ion bonds with oxygen to produce $\mathrm{H}_{2} \mathrm{O}$ compounds. The characteristics of these two ions are interrelated so that they can reduce the metal content in silica. (Fraenkel, 2015). The reactions that occur in metal oxides can be seen in these following equations:

$$
\begin{gathered}
3 \mathrm{H}_{2} \mathrm{SO}_{4(\mathrm{aq})} \rightarrow 6 \mathrm{H}^{+}+3 \mathrm{SO}_{4}{ }^{2-} \\
\mathrm{Fe}_{2} \mathrm{O}_{3(\mathrm{~s})}+6 \mathrm{H}^{+}+3 \mathrm{SO}_{4}{ }^{2-} \rightarrow \mathrm{Fe}_{2}\left(\mathrm{SO}_{4}\right)_{3(\mathrm{aq})}+3 \mathrm{H}_{2} \mathrm{O}_{(\mathrm{l})}
\end{gathered}
$$

Silica produced with purification using $\mathrm{H}_{2} \mathrm{SO}_{4} 20 \%$ has silica content of $98.2 \%$. Impurity compounds and metal oxides are very low with $\mathrm{Mn}, \mathrm{Fe}$, and $\mathrm{Ca}$ levels respectively $0.066,0.531,0.95 \%$. This shows that silica from geothermal solid waste can be synthesized to be developed as a material for making silica adsorbent. 


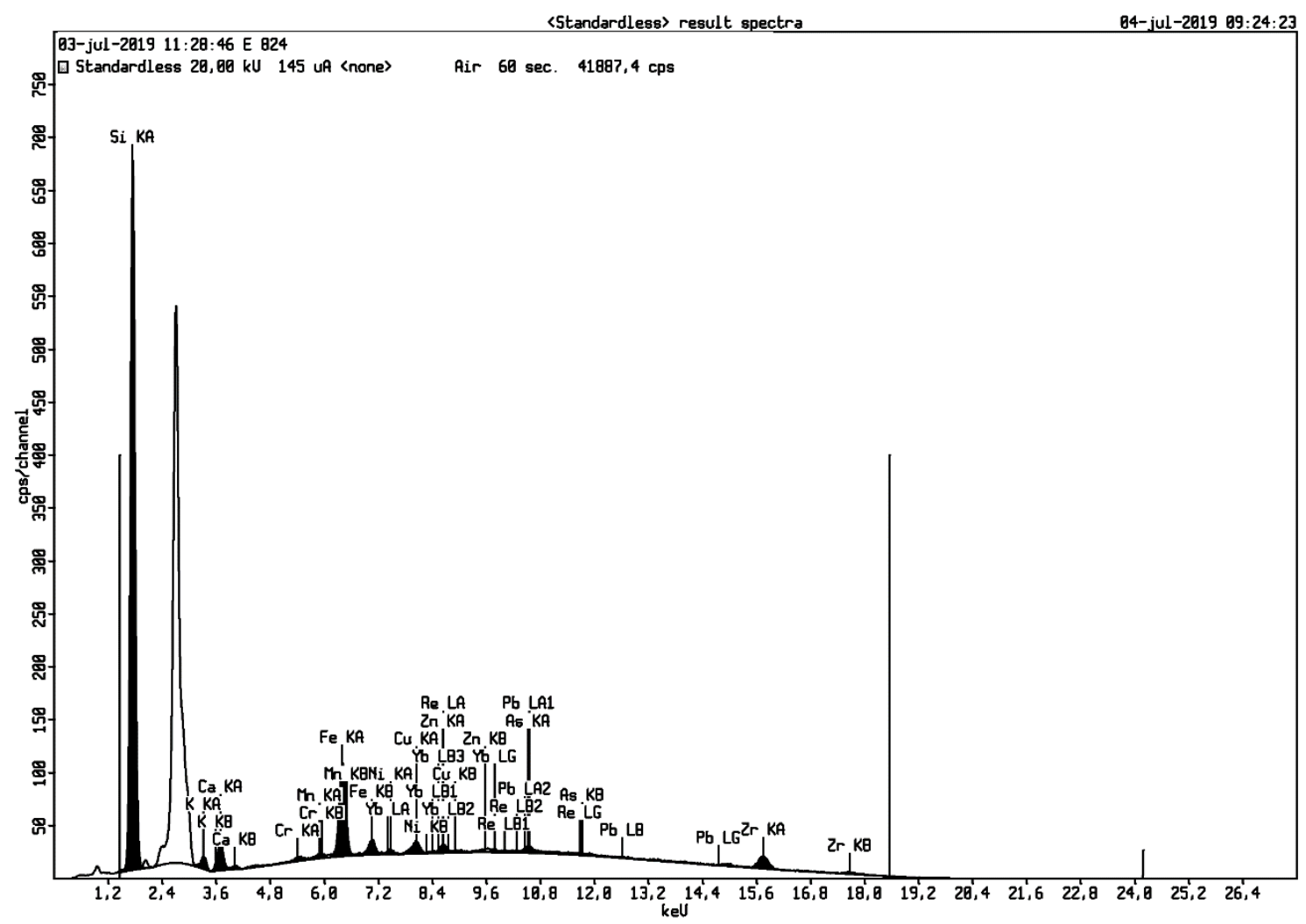

Figure 1. XRF spectra of geothermal silica prior to leaching process

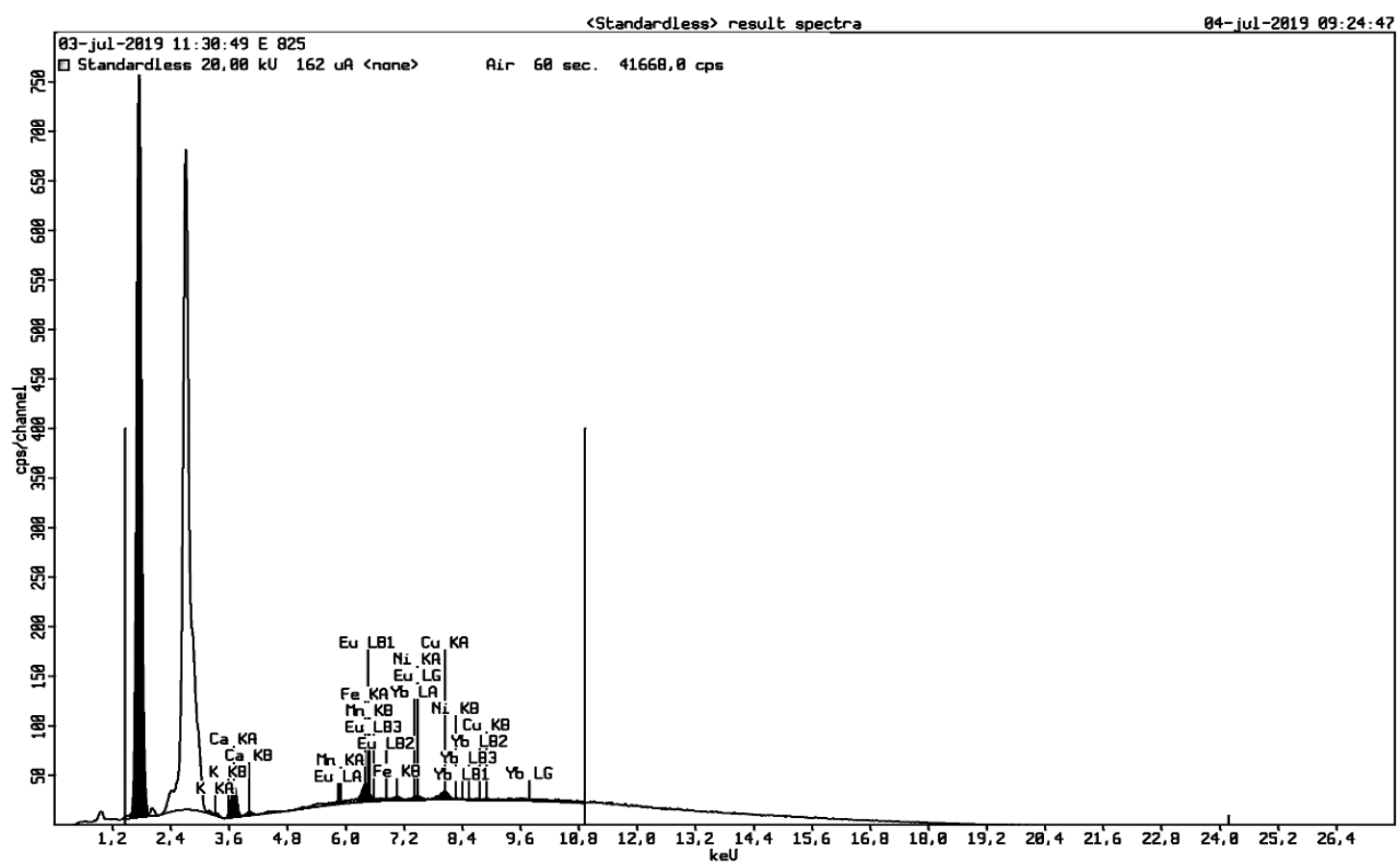

Figure 2. XRF spectra of geothermal silica post to leaching process 
Table 1. XRF Analysis of Geothermal Silica

\begin{tabular}{cccc}
\hline Element & $\begin{array}{c}\text { Before } \\
\text { Purification (\%) }\end{array}$ & Element & $\begin{array}{c}\text { After } \\
\text { Purification (\%) }\end{array}$ \\
\hline $\mathrm{Si}$ & 86.30 & $\mathrm{Si}$ & 93.20 \\
$\mathrm{Sc}$ & 0.11 & $\mathrm{Mn}$ & 4.40 \\
$\mathrm{Nd}$ & 12.00 & $\mathrm{Mg}$ & 0.59 \\
$\mathrm{Ca}$ & 1.10 & $\mathrm{Ca}$ & 0.92 \\
$\mathrm{Cr}$ & 0.95 & $\mathrm{Cr}$ & 0.88 \\
\hline
\end{tabular}

\subsection{Silica Aerogel Synthesis}

The schematic diagram of silica aerogel preparation is shown in Fig. 3. Synthesis of silica aerogel ensued through the sol-gel stage where contact between silica and $\mathrm{NaOH}$ formed a solution of $\mathrm{Na}_{2} \mathrm{SiO}_{3}$ precursor replacing the $\mathrm{Si}-\mathrm{OH}$ silanol group into $\mathrm{Si}-\mathrm{ONa}$ ionic bonds. In this manner, $\mathrm{Na}_{2} \mathrm{SiO}_{3}$ dissolved in water and later subjected to hydrolysis to transform into silicic acid $\mathrm{Si}(\mathrm{OH})_{4}$ through the addition of $\mathrm{HCl}$. The polycondensation of $\mathrm{Si}(\mathrm{OH})_{4}$ caused the formation of colloidal spherical silica with hydroxyl groups. Then, silica hydrogel bonding siloxane (Si-O-Si) groups was formed by inducing polycondensation by adding IPA. After washing and drying at atmospheric pressure, silica aerogel was obtained as the final product. Several studies have succeeded in synthesizing aerogel under atmospheric conditions (Feng et al., 2018; Lee et al., 2017). Therefore ambient pressure drying conditions can be used to produce silica aerogel. The research that has been done obtained surface area and pore volume respectively $819 \mathrm{~m}^{2} / \mathrm{g}, 12.00 \mathrm{~nm}$ and 945,8 $\mathrm{m}^{2} / \mathrm{g}, 3.8 \mathrm{~nm}$ (Feng et al., 2018; Lee et al., 2017).

$\mathrm{Na}_{2} \mathrm{SiO}_{3}+2 \mathrm{HCl}+(\mathrm{n}-1) \mathrm{H}_{2} \mathrm{O} \rightarrow 2 \mathrm{NaCl}+\mathrm{SiO}_{2} \cdot \mathrm{nH}_{2} \mathrm{O}$
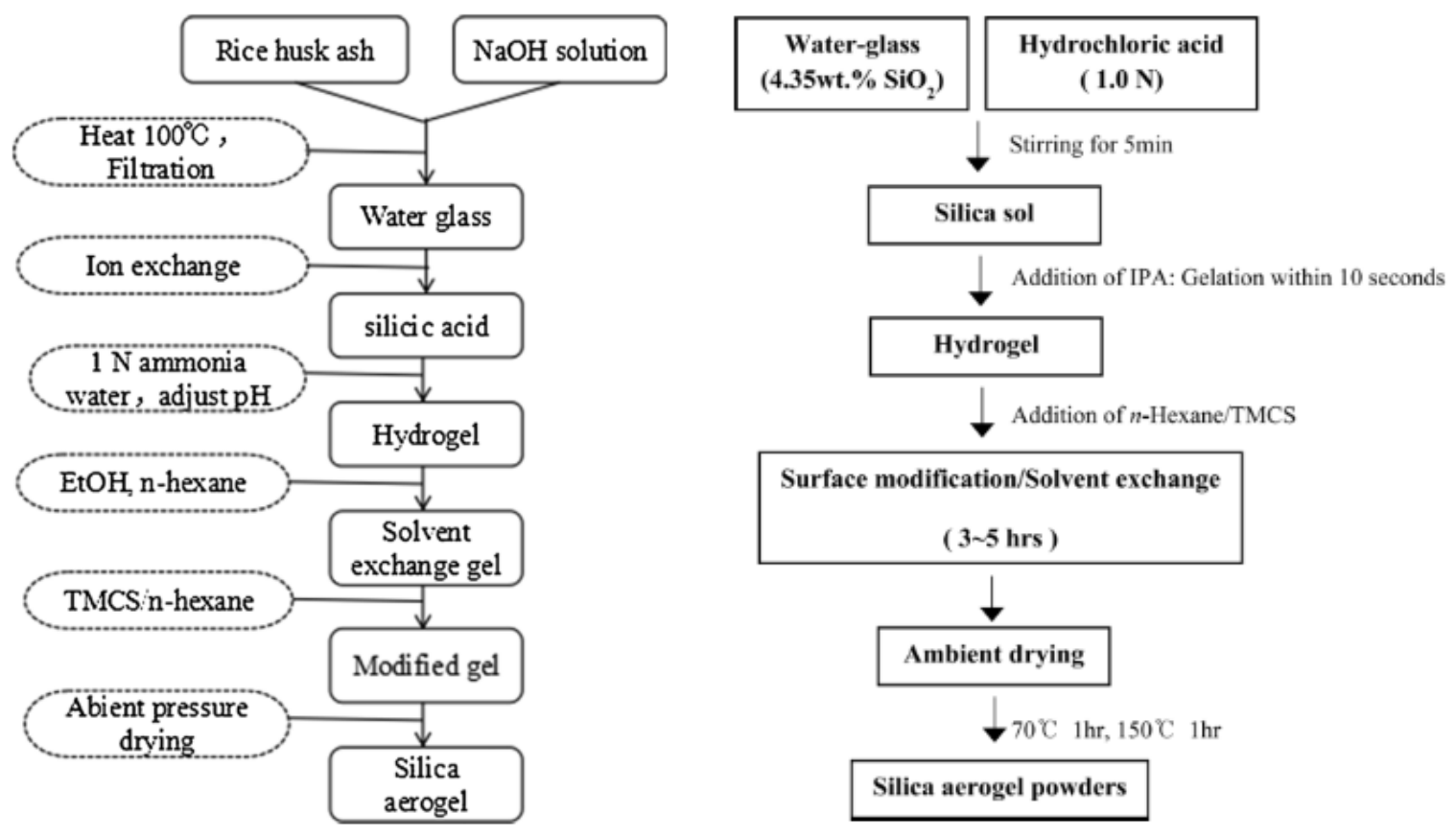

Figure 3. Flowchart for synthesis of water glass to silica aerogel (Feng et al., 2018; Lee et al., 2017) 


\subsection{Adsorbent Coloumn Preparation for Biogas Purifsied}

Figure 4. shows an experimental schematic for $\mathrm{CO}_{2}$ purification with a fixed-bed two columns (Kusrini et al., 2017). The size of the fixed-bed column adsorption is 15 $\mathrm{cm}$ in length and $0.8 \mathrm{~cm}$ in diameter. Biogas is used from the Palm Oil Mill Effluent (POME). This research uses zeolite $(2 \mathrm{M})$ adsorbent coated with $2.5 \mathrm{~g}$ chitosan. The formula is shown in table 1. Surface areas are 39.06 and $8.25 \mathrm{~m}^{2} / \mathrm{g}$. While the average adsorption capacity is $8.5 \mathrm{~nm}$. The results obtained are zeolite $(2 \mathrm{M})$ coated with chitosan that can absorb $\sim 83 \% \mathrm{CO}_{2}$ adsorption. This shows that the amine group contained in chitosan is capable in binding $\mathrm{CO}_{2}$ from biogas from POME.

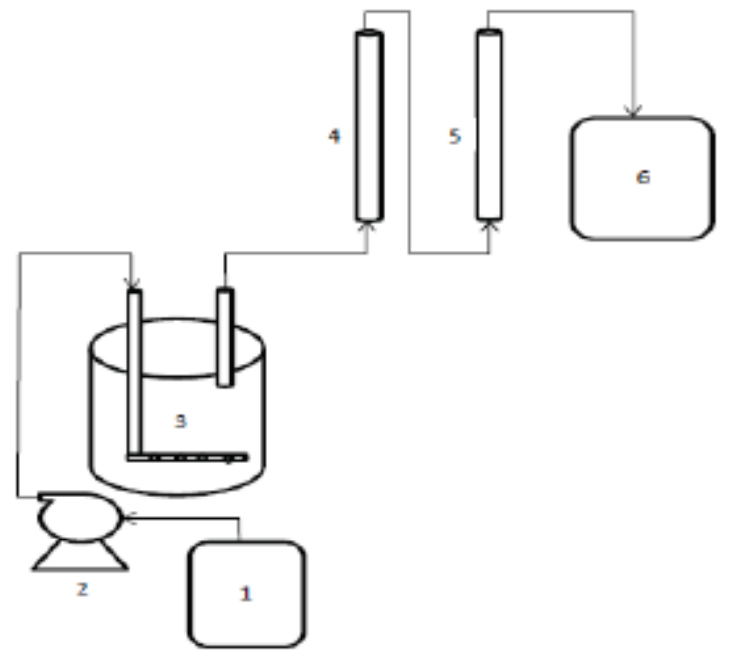

Figure 4.. Schematic process for purification of biogas with zeolite/chitosan (Kusrini et al., 2017)

Table 2. Elemental analysis of zeolit coated chitosan (Kusrini et al., 2017)

\begin{tabular}{cc}
\hline Element & \%weight composition \\
\hline $\mathrm{C}$ & 4.23 \\
$\mathrm{O}$ & 50.68 \\
$\mathrm{Na}$ & 2.41 \\
$\mathrm{Al}$ & 6.93 \\
$\mathrm{Si}$ & 30.94 \\
$\mathrm{~K}$ & 1.85 \\
$\mathrm{Ca}$ & 1.24 \\
$\mathrm{Fe}$ & 1.71 \\
$\mathrm{Si} / \mathrm{Al}$ Ratio & 4.31
\end{tabular}

According to (Kusrini et al., 2017; Lee et al., 2017), the required silica weigh is $30.94 \% \mathrm{wt}$ and $4.35 \%$ wt. Whereas the geothermal solid waste silica shows a relatively high $\mathrm{Si}$ content of $98.2 \%$ as shown in Figure 5. This shows that geothermal solid waste has the potential to be developed as a source of silica as a material for making $\mathrm{CO}_{2}$ adsorbent.

Therefore, the innovation is to use silica sources from geothermal waste. Adsorbent used in this research denoted as chitosan coating to silica aerogel. The schematic process for further research is shown in Fig. 5. The height of the packed column adsorption with the length is $15 \mathrm{~cm}$ and the diameter is $5 \mathrm{~cm}$. The biogas used is artificial biogas, i.e. mixture of methane $(70 \%)$ and carbondioxide $(30 \%)$.

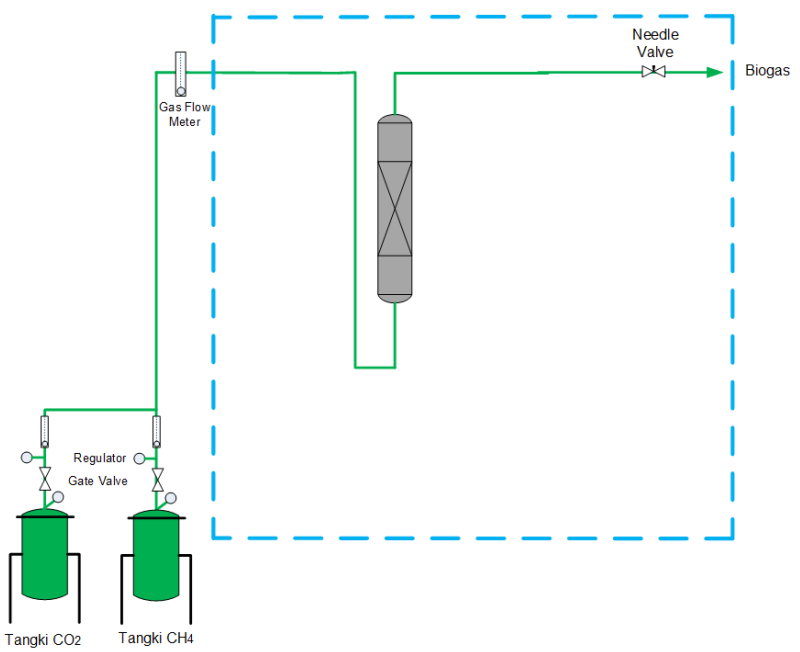

Figure 5. Proposed schematic process for purification biogas with silica aerogel coated chitosan

\subsection{Response Data of Kinetics Study}

The gas adsorption kinetics in silica aerogel can be calculated by the pseudo first and second order (Loganathan et al., 2014).

\section{A. Pseudo First Order}

The Calculation of adsorption kinetics with equations (9):

$$
\frac{d q}{d t}=k_{f}\left(q_{e}-q_{t}\right)
$$

$\mathrm{q}_{\mathrm{e}}(\mathrm{mmol} / \mathrm{g})$ and $\mathrm{q}_{\mathrm{t}}(\mathrm{mmol} / \mathrm{g})$ represent the number of the adsorbed $\mathrm{CO}_{2}$. $\mathrm{q}_{\mathrm{e}}$ can be obtained when the equilibrium of the weight of silica aerogel after $\mathrm{CO}_{2}$ gas flowed under conditions of constant temperature and pressure after silica aerogel adsorbing $\mathrm{CO}_{2}$ gas at a certain time. $\mathrm{kf}\left(\mathrm{s}^{-1}\right)$ indicates the constant of first order (Loganathan et al., 2014). After equation (9) is integrated with boundary conditions ( $\mathrm{t}=0, \mathrm{qt}=0, \mathrm{t}=\mathrm{t} \infty$, and $\mathrm{q}_{\mathrm{t}}=\mathrm{q}_{\mathrm{e}}$ ), equation (10) is gained.

$$
q_{t}=q_{e}\left(1-e^{-k_{f} t}\right)
$$

The value of $\mathrm{k}_{\mathrm{f}}$ for adsorption of $\mathrm{CO}_{2}$ on silica aerogel under various temperature and pressure is obtained from equation (10) (Loganathan et al., 2014).

\section{B. Pseudo second order}

Adsorption kinetic rate can be showed as equation (11):

$$
\frac{d q t}{d t}=k_{s}\left(q_{e}-q_{t}\right)^{2}
$$


The value of $\mathrm{q}_{\mathrm{e}}$ and $\mathrm{q}_{\mathrm{t}}$ will be determined by weight difference $(\Delta \mathrm{W}) . \mathrm{k}_{\mathrm{s}}\left(\mathrm{g} \mathrm{gmol}^{-1} \mathrm{~s}^{-1}\right)$ indicates the constant of second order rate. After equation (11) is integrated with boundary conditions $\left(\mathrm{t}=0, \mathrm{q}=0, \mathrm{t}=\mathrm{t} \infty\right.$, and $\left.\mathrm{q}_{\mathrm{t}}=\mathrm{q}_{\mathrm{e}}\right)$, equation (12) is gained.

$$
q_{t}=\frac{q^{2} e^{k_{s} t}}{1+q_{e} k_{s} t}
$$

the values of $\mathrm{k}_{\mathrm{s}}$ for entire evaluated temperature and pressure conditions are gained based on equation (12) (Loganathan et al., 2014).

\section{Conclusions}

The content of geotermal silica waste still contains a lot of impurities, so it needs to be purified and it can be synthesized into silica aerogel. The remaining geothermal can act as adsorbents to silica aerogel coated with chitosan by using packed column. The data obtained is the equation of kinetic data from the differences in the weight of silica that has adsorbed $\mathrm{CO}_{2}$. This shows that silica from geothermal waste has the potential as a $\mathrm{CO}_{2}$ capture. Therefore, the improvement of innovation in the future of this research is to prepare chitosan coating silica aerogel to adsorbent.

\section{Acknowledgment}

Much appreciation goes to the Advanced Materials Laboratory (AMaL) and colleagues who have provided support throughout the course of this study.

\section{REFERENCES}

[1] Al Mamun, M. R., \& Torii, S. (2017). Enhancement of Methane Concentration by Removing Contaminants from Biogas Mixtures Using Combined Method of Absorption and Adsorption. International Journal of Chemical Engineering, 2017. https://doi.org/10.1155/2017/7906859

[2] Anas Boussaa, S., Kheloufi, A., Boutarek Zaourar, N., \& Bouachma, S. (2017). Iron and aluminium removal from Algerian silica sand by acid leaching. Acta Physica Polonica A, 132(3), 1082-1086. https://doi.org/10.12693/APhysPolA .132 .1082

[3] Chen, S. J., Tao, Z. C., Fu, Y., Zhu, M., Li, W. L., \& Li, X. D. (2017). $\mathrm{CO}_{2}$ separation from offshore natural gas in quiescent and flowing states using $13 \mathrm{X}$ zeolite. Applied Energy, 205(September), 1435-1446. https://doi.org/10.101 6/j.apenergy.2017.09.084

[4] de Fátima Júlio, M., Soares, A., Ilharco, L. M., Flores-Colen, I., \& de Brito, J. (2016). Aerogel-based renders with lightweight aggregates: Correlation between molecular/pore structure and performance. Construction and Building Materials, 124, 485-495. https://doi.org/10.1016/j.conbuild mat.2016.07.103

[5] Feng, Q., Chen, K., Ma, D., Lin, H., Liu, Z., Qin, S., \& Luo, Y. (2018). Synthesis of high specific surface area silica aerogel from rice husk ash via ambient pressure drying. Colloids and Surfaces A: Physicochemical and Engineering Aspects, 539(November 2017), 399-406. https://doi.org/10. 1016/j.colsurfa.2017.12.025

[6] Fraenkel, D. (2015). Structure and ionization of sulfuric acid in water. New Journal of Chemistry, 39(7), 5124-5136. https://doi.org/10.1039/c5nj00167f

[7] Ghrab, S., Benzina, M., \& Lambert, S. D. (2017). Copper Adsorption from Wasterwater Using Bone Charcoal. Advances in Materials Physics and Chemistry, 07(05), 139147. https://doi.org/10.4236/ampc.2017.75012

[8] Gozmen Şanli, B., Uludamar, E., \& Özcanli, M. (2019). Evaluation of energetic-exergetic and sustainability parameters of biodiesel fuels produced from palm oil and opium poppy oil as alternative fuels in diesel engines. Fuel, 258(September), 116116. https://doi.org/10.1016/j.fuel.201 9.116116

[9] Hairul, N. A. H., Shariff, A. M., \& Bustam, M. A. (2017). Process behaviour in a packed absorption column for high pressure $\mathrm{CO}_{2}$ absorption from natural gas using PZ + AMP blended solution. Fuel Processing Technology, 157, 20-28. https://doi.org/10.1016/j.fuproc.2016.11.008

[10] Kamal, M. A., Bibi, S., Bokhari, S. W., Siddique, A. H., \& Yasin, T. (2017). Synthesis and adsorptive characteristics of novel chitosan/graphene oxide nanocomposite for dye uptake. Reactive and Functional Polymers, 110, 21-29. https://doi.org/10.1016/j.reactfunctpolym.2016.11.002

[11] Khalil, M., Berawi, M. A., Heryanto, R., \& Rizalie, A. (2019). Waste to energy technology: The potential of sustainable biogas production from animal waste in Indonesia. Renewable and Sustainable Energy Reviews, 105(July 2018), 323-331. https://doi.org/10.1016/j.rser.201 9.02.011

[12] Kong, Y., Shen, X., Cui, S., \& Fan, M. (2015). Development of monolithic adsorbent via polymeric sol-gel process for low-concentration $\mathrm{CO}_{2}$ capture. Applied Energy, 147, 308317. https://doi.org/10.1016/j.apenergy.2015.03.011

[13] Kusrini, E., Lukita, M., Gozan, M., Susanto, B. H., Nasution, D. A., Rahman, A., \& Gunawan, C. (2017). Enrichment process of biogas using simultaneous Absorption Adsorption methods. AIP Conference Proceedings, 1826. https://doi.org/10.1063/1.4979244

[14] Kusworo, T. D., Qudratun, B., Utomo, D. P., Ramadhan, I. R., \& Indriyanti. (2018). Synthesis and Characterization of Nano Hybrid Membrane PES-TiO2 for Biogas Purification: Combination Effect of Ultra Violet and Cross-Linking. MATEC Web of Conferences, 156, 2-5. https://doi.org/10.1 051/matecconf/201815608006

[15] Lee, S. E., Ahn, Y. S., Lee, J. S., Cho, C. H., Hong, C. K., \& Kwon, O. H. (2017). Ambient-pressure drying synthesis of high-performance silica aerogel powders by controlling hydrolysis reaction of water glass. Journal of Ceramic Processing Research, 18(11), 777-782.

[16] Loganathan, S., Tikmani, M., Edubilli, S., Mishra, A., \& Ghoshal, A. K. (2014). $\mathrm{CO}_{2}$ adsorption kinetics on 
mesoporous silica under wide range of pressure and temperature. Chemical Engineering Journal, 256, 1-8. https://doi.org/10.1016/j.cej.2014.06.091

[17] Melikoglu, M., \& Turkmen, B. (2019). Food waste to energy: Forecasting Turkey's $\mathrm{s}$ bioethanol generation potential from wasted crops and cereals till 2030. Sustainable Energy Technologies and Assessments, 36(March), 100553. https://doi.org/10.1016/j.seta.2019.100 553

[18] Purnomo, A., Dalanta, F., Oktaviani, A. D., \& Silviana, S. (2018). Superhydrophobic coatings and self-cleaning through the use of geothermal scaling silica in improvement of material resistance. AIP Conference Proceedings, 2026. https://doi.org/10.1063/1.5065037

[19] Sneddon, G., Ganin, A. Y., \& Yiu, H. H. P. (2015). Sustainable CO 2 Adsorbents Prepared by Coating Chitosan onto Mesoporous Silicas for Large-Scale Carbon Capture Technology. Energy Technology, 3(3), 249-258. https://doi.org/10.1002/ente.201402211
[20] Vazquez, N. I., Gonzalez, Z., Ferrari, B., \& Castro, Y. (2017). Synthesis of mesoporous silica nanoparticles by sol-gel as nanocontainer for future drug delivery applications. Boletin de La Sociedad Espanola de Ceramica y Vidrio, 56(3), 139-145. https://doi.org/10.1016/j.bsecv.20 17.03.002

[21] Yi, H., Li, Y., Tang, X., Li, F., Li, K., Yuan, Q., \& Sun, X. (2015). Effect of the adsorbent pore structure on the separation of carbon dioxide and methane gas mixtures. Journal of Chemical and Engineering Data, 60(5), 1388 1395. https://doi.org/10.1021/je501109q

[22] Zhang, L., Yu, C., Zhao, W., Hua, Z., Chen, H., Li, L., \& Shi, J. (2007). Preparation of multi-amine-grafted mesoporous silicas and their application to heavy metal ions adsorption. Journal of Non-Crystalline Solids, 353(44-46), 4055-4061. https://doi.org/10.1016/j.jnoncrysol.2007.06.018 